\title{
TRANSITANDO PELO ITINERÁRIO TERAPÊUTICO: DISCURSO E SABERES NA AMAZÔNIA TOCANTINA
}

\author{
TRANSITING THE THERAPEUTIC ITINERARY: SPEECH \\ AND KNOWLEDGE IN AMAZÔNIA TOCANTINA
}

\author{
Andrea Silva Domingues ${ }^{1}$, Marcia de Jesus Oliveira Valente ${ }^{2}$ \\ O sentido não pára; ele muda de caminho. \\ Eni P. Orlandi.As formas do silêncio.
}

\begin{abstract}
RESUMO:Considerando as narrativas orais como fatos de linguagem que se materializam nos discursos, o artigo apresentado baseia-se nas narrativas dos moradores das margens e das matas do Rio Cupijó. Tendo como objetivo compreender o itinerário terapêutico e as práticas de cura de parte da Amazônia Tocantina, realizamos um estudo das formas de fazer e os sentidos das práticas culturais em torno dos tratamentos de saúde, além da medicina convencional. Metodologicamente, trabalhamos com a análise de entrevistas orais que foram realizadas com moradores (as) da Vila Baia - Cametá-Pará. Categorias como memória, discurso e cultura são fundamentais neste estudo para a compreensão do passado e seu sentido no presente. O trabalho foi desenvolvido na interlocução da Análise de Discurso e da História Social, um caminho que nos levou a compreender como os sujeitos constituem a cultura na e pela linguagem como produtora de sentidos e resistência no tempo presente.
\end{abstract}

PALAVRAS-CHAVE: discurso; saúde; saberes; itinerário terapeutico

\begin{abstract}
Considering the oral narratives as facts of language that materialize in the speeches, the article presented is based on the narratives of the residents of the banks and forests of the Cupijo River. Aiming to understand the therapeutic itinerary and healing practices of part of the Amazônia Tocantina, we realized a study of the ways of doing and the senses of cultural practices around health treatments, beyond to conventional medicine. Methodologically, we worked with the analysis of oral interviews that were conducted with residents of Vila Baia - Cametá-Pará. Categories such as memory, speech and culture are fundamental in this study for understanding the past and its meaning in the present. The work was developed in the interlocution of Discourse Analysis and Social History, a path that led us to understand how people constitute culture through language as a producer of senses and resistance in the present time.
\end{abstract}

\footnotetext{
${ }^{1}$ Doutora em História pela PUC-SP com Pós-Doutorado pelo LABEURB-UNICAMP em Análise de Discurso. Professora visitante sênior do PPG em Educação e Cultura da UFPA - PROCAD AMAZÔNIA. Pesquisa com apoio PROCAD-AMAZÔNIA; CAPES.

2 Mestranda do Programa de Pós-Graduação em Educação e Cultura do Campus Universitário do Tocantins de Cametá da Universidade Federal do Pará.
} 
KEYWORDS: speech; health; knowledge; therapeutic itinerary

\section{Preâmbulo}

Ao caminhar e navegar pelas estradas, matas e águas da Amazônia Tocantina, buscamos trazer na coonstrução deste texto um olhar histórico e político, para que pudéssemos fugir do anacronismo e melhor compreender as possíveis configurações discursivas na e sobre uma parte deste território permeado de saberes e magias de tempos remotos, mas sempre entendendo que

\footnotetext{
Olhar politicamente é por as dissidências no centro no foco, o traço oposicionista da arte frente aos discursos (a ideologia, a moral, a estética) estabelecidos. Um olhar político aguça a percepção das diferenças como qualidades alternativas frente às linhas respaldadas pela tradição estética ou pela inércia [...]. Um olhar político sabe descobrir as tendências que questionam ou subvertem a ordem estético-ideológica, abrindo trilhas nas formulas da arte realmente existentes (SARLO, 1997, p.60).
}

Para constituir este olhar politico foi necessário, caminhar e navegar pelo rio Cupijó, buscando perceber como é instituída essa região, as muitas memórias e discursos que estabelecem os saberes, as formas de tratar, ensinar e aprender as práticas de cura, observando o presente, o passado, para melhor compreender os discursos produzidos na contemporaneidade pelos narradores e narradoras com quem dialogamos.

Cametá, nosso lócus de pesquisa, conforme dados do Instituto Brasileiro de Geografia e Estatística - IBGE (2012) constitui-se em um município do estado do Pará, da Amazônia brasileira, situado na região do baixo Tocantins, tendo uma população estimada em 2019 de 137.890 habitantes. Possui uma área de 3.081,367 quilômetros quadrados que se relacionam com outras cidades através da via Transcametá, Arapari e Alça Viária. Referente à saúde "a taxa de mortalidade infantil média na cidade é de 14.89 para 1.000 nascidos vivos. As internações decorrentes de diarréias são de 5 para cada 1.000 habitantes".(IBGE,2017)

Por ser uma região entre rios e matas, a maioria da população cametaense vive longe do centro urbano, localizando-se na zona rural. E nosso recorte de pesquisa considera uma das áreas distante do centro urbano, a Vila Baia, em que grande parte dos moradores sobrevive dos recursos naturais ofertados pelas matas e pelas águas do rio Cupijó.

Na busca de problematizar o itinerário terapêutico e as relações sociais constituídas 
por homens e mulheres que vivem na região do Cupijó, mais precisamente a Vila Baia, foi necessário buscar compreender os costumes e culturas em que esses sujeitos estão inseridos, além dos conflitos e formas de resistências que eles usam para sobreviver.

Nesse sentido o diálogo da História Oral com a Análise do Discurso tem sido de grande importância para estas pesquisadoras, pois através das memórias, dos discursos, percebemos as práticas culturais e formas de se fazer dos sujeitos históricos, que possuem representações significativas para a construção identitária e da resistência dos povos da Amazônia Tocantina.

\begin{abstract}
As experiências de vida dos narradores aparecem fortemente associadas a natureza, assim ao transmitir suas lembranças nos revelam sua própria experiência de vida e a transformam em experiência para os seus ouvintes (BOSI, 1994, p. 47).
\end{abstract}

A prática da História Oral com a Análise de Discurso vêm nos conduzindo a novos caminhos, desafiadores, onde buscamos respostas as nossas inquietações; porém esses caminhos também nos levam ao encontro de novas técnicas e sujeitos sociais diferentes.

\title{
Itinerário terapêutico: saúde e doença
}

Os caminhos, que são traçados ao entendimento da relação entre saúde e doença necessitam perpassarem por vários campos de saber, pois, na atual conjuntura, os estudos sobre esses dois universos buscam valorizar abordagens que não se limitam ao paradigma biomédico, contemplando o estado de saúde e doença como uma totalidade, fruto de si e de todo o universo sociocultural que o circunda. Buscamos neste estudo reforçar a importância da interdisciplinaridade, e aqui especificamente das Ciências Humanas com as Ciências Médicas, com a Sáude Coletiva, principalmente no tempo presente que estamos vivenciando problemas concretos com o sistema de sáude pública, no que tange às doenças epidemiológicas como o COVID 19, Malária, Febre Amarela, Gripe Influenza, Dengue, entre outras, para que possamos:

Problematizar os conceitos tidos como verdades inquestionáveis, desnaturalizar os indicadores, evidenciar os reducionismos, mas, sobretudo, trazer para a pauta do debate, a lógica interna dos grupos sociais, que costumam ficar ocultas sob os números e são essenciais para a eficácia das propostas de saúde. Colocando em foco as razões da interculturalidade e a complexidade da experiência humana, com certeza ela dá as mãos às descobertas importantíssimas da epidemiologia moderna, na qual os intelectuais brasileiros têm um lugar de reconhecida competência. (MINAYO, 2000, p. 228) 
Nesse sentido, destacamos que a saúde é um processo inerente ao dinamismo social relacionado a outros processos sociais, no qual cada indivíduo abstrai, processa e exterioriza seu entendimento de sua saúde e doença, a partir da representação sociocultural que elabora frente à realidade em que se insere. Com isso, podemos perceber a importância de se considerar um meio exterior participante na construção da concepção de saúde, que se torna particular para cada indivíduo.

Ao analisar historicamente os processos responsáveis pela construção das sociedades humanas, observamos que cada uma delas foi erguida a partir dos seus próprios meios para superar os embates com a sua sobrevivência e manter assim seus saberes e práticas culturais.

Nessa perspectiva, a natureza social, inerente aos sistemas de organização das sociedades, tornou-se responsável por caracterizar e determinar tais sociedades, frente aos mais variados aspectos culturais. Desse modo, vale ressaltar uma experiência comum a todos os indivíduos: o adoecimento e as formas de se lidar com ele.

A doença, embora seja uma condição que acomete todo e qualquer ser vivente, pode ser concebida por ângulos distintos. Sob esse prisma, a compreensão em torno desse fenômeno demanda não só a análise biológica, como também requer uma avaliação sobre as suas dimensões sociais, étnicas, psicológicas, ecológicas e, sobretudo, culturais. Em consequência disso, os aspectos etiológicos e terapêuticos encontram-se intimamente associados à questões de ordem biomédica com as circunstâncias humanas em que esses elementos se inserem.

Portanto, a maneira como uma população adoece e, igualmente, os tratamentos apresentados, podem ser considerados reflexos diretos das particularidades sociais nas quais se encontram. Em consequência, o conhecimento sobre o conjunto de valores construídos acerca dos processos de saúde-doença torna-se uma peça fundamental para o entendimento das práticas culturais e estratégias utililizadas em diferentes comunidades como forma de resistência a prática médica ocidental.

Certamente, os estudos sobre a medicina popular não deve ficar restrito à análise da disponibilidade de recursos naturais, assim como na utilização que os indivíduos fazem das plantas medicinais ou extratos animais para a cura, uma vez que esses elementos não são suficientes para a compreensão de como se constrói a escolha desse itinerário terapêutico. Contudo, o fator cultural influencia consideravelmente tal percurso, assim entedemos que; 
Cultura é uma expressão utilizada para representar desde um conjunto de tradições e capacidades inerentes à condição humana até a afirmação de identidades nacionais, de grupos e subgrupos. Refere-se ao enriquecimento do espírito, a valores e normas existentes em determinados contextos históricos e sociais; expressa a conexão orgânica das diversas manifestações de uma época; refere-se a certas atitudes que caracterizam uma instituição (ALVES, 2010, p. 18).

Dessa maneira, o estado psicobiossocial junto às diferentes representações socioculturais em saúde-doença-cuidado constituem elementos fundamentais ao norteamento da escolha para o tratamento à doença ou direcionamento ao enfrentamento a uma determinada mudança que envolva todos os campos do universo humano.

À medida que se tem a necessidade de buscar a resolutividade a uma determinada situação que imprime cuidados, os (as) trabalhadores (as) procuram no contexto que se inserem a construção das representações socioculturais sobre seu estado psicobiossocial acerca do itinerário terapêutico a ser utilizado.

Portanto, analisar a importância que se faz do uso da medicina popular, como esse itinerário é manipulado na vida dos que residem em áreas de difícil acesso, onde o conhecimento do senso comum e a influência sociocultural fazem-se determinantes, onde os saberes são construidos de geração a geração, e a população apresenta uma relação única e profunda com a natureza, indubitavelmente se consubstancia em uma ação imprescíndivel ao entendimento e respeito as práticas vivenciadas por esses sujeitos.

Nossos estudos perpassam pelas escolhas que os sujeitos sociais da pesquisa realizam para amenizar ou curar um problema de saúde. Para que possamos compreender os determinantes que influenciam suas decisões, elegemos importante destinar um olhar político e histórico, que busque entender o movimento constante que permea nas práticas culturais que se consubstanciam em itinerário terapêutico.

O itinerário terapêutico pode ser entendido como um processo onde os indivíduos ou grupos sociais escolhem, avaliam e aderem (ou não) algum tipo de tratamento (ALVES; SOUSA, 1999). Mângia e Muramoto (2008) ressaltam que as experiências dos sujeitos sofrem modificações no decorrer do agir cotidiano e da busca por soluções práticas para os processos de adoecimento.

Abordamos, neste texto, o itinerário terapêutico, destacando o uso de plantas medicinais como escolha de itinerário, uma vez que vem se consubstanciando, no que se pode acompanhar nos discursos dos sujeitos entrevistados, em ações de resistência materializada através de suas táticas (CERTEAU, 1994, p. 121), negando o 
desaparecimento de suas práticas culturais e formas de se fazer.

O uso das plantas medicinais no Brasil é uma prática cultural desde tempos remotos que vem sendo praticada até a contemporaneidade por diferentes gerações, sendo este costume uma tradição, principalmente no que tange a sintomas primários de cuidados com a saúde. Em muitas comunidades tradicionais (ribeirinhas, quilombolas, indígenas, rurais) as plantas medicinais é um dos meios mais acessíveis como tratamento para diversas doenças, e estas são cultivadas em seus quintais das mais variadas formas (BEVILACQUA, 2010).

Desse modo, o conhecimento sobre o conjunto de valores construídos acerca dos processos de saúde-doença torna-se uma peça fundamental para o entendimento das práticas culturais e estratégias utilizadas em diferentes comunidades como forma de resistência a prática médica ocidental.

Nessa perspectiva, buscamos entender as práticas referentes a medicina popular para lidar com os agravos em saúde e/ou doença, considerando que o levantamento e descrição de itinerário terapêutico permite compreender os caminhos e ações adotadas por sujeitos e coletividades diante das condições sociais, políticas e intersubjetivas disponíveis para o cuidado com a vida e o tratamento do adoecimento (GERHARDT, 2006).

A escolha desse itinerário terapêutico não necessariamente segue caminhos ou esquemas pré-estabelecidos, pelo contrário, envolve construção subjetiva individual e também coletiva. Entender as influências herdadas pelos seus ancestrais, assim como as trazidas com o advento da modernidade, constituem em conhecimentos imprescindíveis para que possamos compreender quais as decisões efetuadas por esses sujeitos.

Quando alguém se depara com um acometimento de dor de cabeça, dores musculares, nas articulações, diarréia, vômito, entre outras reações associadas ao processo de saúde e doença, recorrendo-se aos remédios caseiros (chás, banhos de ervas, fumentações, xaropes, à base de plantas medicinais e de extratos advindos de animais silvestres), a benzedeira que utiliza galhos de plantas para realizar as benzeções, a curandeiras e parteiras, ao pai de santo, à reza do padre ou a oração do pastor, ou ainda a consulta médica e uso de medicamentos provenientes da indústria farmacológica ou alopática, estará se apropriando de um itinerário terapêutico.

No que concerne às práticas religiosas associadas às formas de cuidado à saúde, no dizer de Santos e Ribeiro (2015), elas operam como uma tecnologia que possibilita o acolhimento da pessoa no momento de sofrimento e angústia, ajudando a lidar com situações estressoras. Nesse sentido, auxiliam na obtenção de um estado integral de saúde 
(física, psíquica, espiritual), que vai muito além de um determinado procedimento ou etapa de tratamento que deve ser seguido.

No uso das plantas medicinais em comunidades, de acordo com Gadelha et al. (2013), o que está em jogo não é a cientificidade comprovada da planta, mas sim o efeito de resposta dela no cotidiano de seus usuários. O conhecimento popular é produzido por meio do valor empírico aliado à crença sobre seus efeitos, que é fortalecida diante da capacidade de resposta sobre os agravos e/ou doenças, enquanto conhecimento tradicional passado de geração em geração.

A saúde é um processo inerente ao dinamismo social relacionado com outros processos sociais, no qual cada indivíduo percebe de um modo particular, exteriorizando seu entendimento de sua saúde e doença, a partir da representação sociocultural que elabora frente à realidade em que se insere. Com isso, podemos perceber a importância de se considerar um meio exterior participante na construção da concepção de saúde, que se torna particular para cada indivíduo.

Observemos a a Portaria n ${ }^{\circ}$ 104, do Ministério da Saúde do Brasil, de 25 de janeiro de 2011,

Art. $1^{\circ}$ Definir as terminologias adotadas em legislação nacional, conforme o disposto no Regulamento Sanitário Internacional 2005 (RSI 2005):

I - Doença: significa uma enfermidade ou estado clínico, independentemente de origem ou fonte, que represente ou possa representar um dano significativo para os seres humanos;

II - Agravo: significa qualquer dano à integridade física, mental e social dos indivíduos provocado por circunstâncias nocivas, como acidentes, intoxicações, abuso de drogas, e lesões auto ou heteroinfligidas;

Como é descrito na Portaria, há uma definição nacional para as terminologias doença e saúde, ambas interferem nos modos de vida do ser humano, principalmente quando estamos tratando de comunidades do interior da Amazônia, as formas de lidar e comprender os males do corpo são distintas, havendo desta maneira,

Obstáculo ao ajustamento das farmacopeias às novas formas da medicina e fisiologia. Alguns sistemas puramente simbólicos conservaram sua solidez até o final da era clássica, transmitindo, mais do que receitas, mais do que segredos técnicos, imagens e símbolos surdos que se ligavam a um onirismo imemorial. (FOUCAULT, 2010, p. 336)

As concepções de cura adotadas pelas mulheres e homens das matas, dos rios e 
igarapés do Cupijó são permeadas de sentidos, significados que simbolizam práticas culturais de tempos remotos, de técnicas e saberes tradicionais que foram se hibridando com a natureza, a fé e as necessidades do tempo presente.

O itinerário terapêutico discursivizado pelos nossos narradores e narradoras trazem marcas de acontecimentos diversos, que constroem sentidos para este intinerário como um trajeto cheio de caminhos, opções adotadas pelos sujeitos ou comunidades como mecanismo de preservação ou cuidados primários de saúde, nos quais podem mobilizar recursos caseiros, religiosos, biomédios entre outros. São momentos que reúnem práticas e saberes para resolução de problemas e tratamento de um problema de saúde.

\section{Discurso e práticas de cura}

Frente a tantos mistérios que circundam o cenário amazônico, faz-se necessário destinar um cuidado minucioso à experiência de enfermidade que o indivíduo possui, diante do meio que se insere, para podermos entender as suas necessidades, assim como a percepção de saúde, doença e cultura que cada um constrói para si, o que influenciará na escolha dos mecanismos de tratamento que responderá a sua aflição, expectativas e cura de sua doença.

A partir desse contexto, podemos destacar que as concepções que se atribuem aos conceitos de saúde, doença e cuidado não se correspondem, somente a história social e da herança cultural, ou seja, extrapola a experiência individual, envolvendo a coletividade, seus valores e costumes intersubjetivamente compartilhados que permeiam nas suas representações socioculturais (GOMES, 2002).

As abordagens pela vertente da Antropologia da Saúde consideram que se trata de um campo de estudo emergente no Brasil em processo crescente de autonomia. Frente a isso,

O discurso antropológico brasileiro sobre saúde insiste nas forças culturais e sociais como fatores determinantes das práticas e das representações nesse campo. O programa de pesquisa da antropologia da saúde no Brasil não nega os conhecimentos biológicos, porém concebe o corpo e as doenças como aspectos construídos relacionalmente (LANGDON, 2012, p. 7).

Para resolver seus problemas de saúde, os sujeitos sociais, conforme os contextos socioculturais que pertencem, buscam selecionar alternativas de tratamento que sejam pertinentes ao cumprimento de suas expectativas, de modo que possam corresponder às 
aflições, à disponibilidade de recursos e a cura.

À medida que se tem a necessidade de buscar a resolutividade a uma determinada situação que imprime cuidados, os sujeitos que se deparam frente a um problema de saúde, procuram no contexto que se inserem a construção das representações socioculturais sobre seu estado psicobiossocial acerca do itinerário terapêutico.

Portanto, analisar como se realiza esse itinerário na vida dos que vivem em áreas de difícil acesso, o qual se agrava em períodos chuvosos, onde o conhecimento do senso comum e a influência sociocultural fazem-se determinantes, como ocorre entre as populações tradicionais rurais, onde a população apresenta uma relação única e profunda com a natureza, indubitavelmente se consubstancia em um desafio, que buscamos dialogar com nossos (as) narradores (as), e para isto consideramos que "o sujeito é constituído pela sua relação com a linguagem e interpelado pela ideologia, [que] individua-se pela articulação simbólica e política produzida" pelas artimanhas oficiais do "Estado, seja pelas Instituições, seja pelos discursos que este engendra e administra" (ORLANDI, 2016, p. 10), que a compreensão da categoria discurso torna-se fundamental para realização deste estudo, principalmente quando propomos um diálogo com diferentes áreas do saber como a História e a Análise do Discurso.

As práticas de cura, a medicina popular absorvem a historicidade, adaptam suas formas de resistência desta maneira devemos estar atentas que o "discurso em si não diz nada, pelo contrário, é necessário chamar atenção para os diferentes discursos que são produzidos acerca de um mesmo tema, e notar que da confluência e da intersecção destes é que um acontecimento pode surgir" (COUTO, 2011, p. 2).

Por isso que, ao tratar do discurso sobre as práticas de cura, tratamento das dores do corpo, que nos preocupamos acompanhar o movimento da história, do discurso, pois "o discurso é assim palavra em movimento, prática de linguagem: com o estudo do discurso observa-se o homem falando" (ORLANDI, 2015, p. 13). É nestes diferentes discursos, nas narrativas de homens e mulheres que trilhamos nosso trabalho e passamos agora neste texto a dialogar com recortes das narrativas de alguns de nossos narradores.

Ao falar do itinerário terapêutico com o senhor Joaquim, morador do Cupijó que escolhe das ervas para tratar das suas enfermidades, dos seus familiares, e daqueles que recorrem ao seu auxílio, em seus gestos e expressões faciais, transmitiu-nos uma nítida satisfação em ser conhecedor dos benefícios da cura pelas ervas e o que elas provocam ao organismo humano, assim como a de poder constatar que seu conhecimento acerca dos saberes tradicionais, em alguns casos, mostra-se alcançar resultados de melhora mais 
eficiente que os da Ciências da Saúde.

\begin{abstract}
Num tempu que minha mulhê adueceu. Com problema. Ela foi operada.E depois da operação ela cuntinuou com sangramento...E aí passô um tempo...Eu falei...A senhora veio lá im casa...Ela conversando comigo...Pergunto e cuntei a situação da mulhê...Qui ela tevi uma operação, continuo com aquilo...Ela fez uma curetagi, continuou cum probrema sério.Vorto no médico...O médico disse que ia continua assim, até carma...Era sangramento toda semana...Aí essa senhora me ensino a fazê a garrafada... Aí comecei fazê...Essa senhora até fez a primera garrafada...Foi qui ela tomô e ela ficô boa, minha mulhê, graça a Deus.... (narrativa de Joaquim Mariano, 2019)
\end{abstract}

Na situação mencionada, Joaquim traz em sua narrativa memórias de um problema de saúde que ocorreu com sua esposa, a qual passou por um processo cirúrgico, denominado de curatagem, após ter perdido um bebê, permanencendo por longos dias sangrando. Após retorno médico, diante da afirmação do profissional da saúde que ela continuaria sangrando por tempo indeterminado até estancar, não se conformou e lançou mão dos saberes tradicionais. Buscou aprender a preparar a chamada garrafada, com senhoras portadoras dessa tradição; preparou suas misturas, deu a sua cônjuge e percebeu que em poucos dias sua saúde havia restabelecido, como ele nos narra "Foi qui ela tomô $e$ ela ficô boa, minha mulhê, graça a Deus". Os saberes tradicionais para Joaquim também sempre estão vinculados à graça de Deus, a fé, que se faz presente no cotidiano dessas comunidades em sua maioria pela religiosidade católica apostólica romana. Ao dizer que sua esposa "Vorto no médico...O médico disse que ia continua assim, até carma." observa-se que a relação médico - paciente estabelecida não resolveu seus problemas de adoecimento do corpo, que satisfazesse suas necessidades daquele momento, a técnica cientifica neste caso indicada, a espera para acalmar o sangramento não tinha sentido de cura para seu Joaquim.

Desse modo, notamos que em algumas situações, após experimentar e observar que as drogas farmacológicas não surtem os efeitos desejáveis e indicados a determinadas enfermidades, os moradores do Cupijó recorrem as plantas medicinais, aos conhecimentos adquiridos a partir das experiências dos mais velhos, para fazer suas misturas artesanais, garrafadas, visando a cura das dores do corpo. Nesse sentido, seu Joaquim nos fala das encomendas que recebe para a produção da garrafada: 
rumô uma mulhê pra lá...I eli veiu aqui pa levá...Porque assim, num tem um conhecimento muito afundu, dissu aí...Aí eu...Eu só faço assim, num momentu certo, né...... (narrativa de Joaquim Mariano, 2019)

Os saberes das matas e dos rios, referentes às formas de cura com o uso das ervas medicinais para Joaquim não têm apenas um sentido comercial ao vender suas garrafadas, ou de caridade ao distribuir para amigos e familiares na comunidade, pois para o mesmo é necessário que se tenha conhecimento especifico da enfermidade do sujeito, é necessário averiguar, ter detalhes para acertar na cura da doença, podendo este momento ser comparado com o exame clinico realizado pelo médico, mas para Joaquim a proposta terapêutica, a confecção da garrafada tem que fazer sentido para quem o procura, neste caso o sujeito paciente; desta forma ele só faz "num momentu certo" e "por incomenda" para as pessoas que o procura seja por indicação ou por já saber que o mesmo utiliza das ervas medicinais para tratamento das dores do corpo.

As práticas de cura realizadas nas matas e rio do Cupijó, certamente, têm muito a acrescentar aos saberes tradicionais, de modo que as gerações mais novas tenham a possibilidade de não apenas conhecer o que seus antepassados escolhiam para o enfrentamento das enfermidades, mas sim de aprenderem com as experiências dos mais velhos, o modo como se constrói as ações para a cura, a fim de que esses conhecimentos possam auxiliar aqueles que os buscam.

No que refere aos itinerários terapêuticos, a senhora Elza em sua narrativa menciona que desde criança lembra sobre a preferência de seus antecedentes, quando passavam por situação de enfrentamento a processsos de saúde e doença, em fazer uso dos saberes tradicionais, pois na maioria dos casos recorriam a benzedeira, parteira, as ervas medicinais, entre outras para a cura dos problemas que afligiam o corpo. Dona Elza nos fala:

\footnotetext{
Moro aqui cinquenta e quatro anos. Nasci aqui no Cupijó memo. Naquela época num tinha negoci, né...De coisa, assim $i$ pro hospital...Só era parteira...Naquela época...Num tinha essi negocio de fazer pré natal, nada...Aí eu nasci mermo em casa...Num fui prospital...Uma parteira...Até qui num mi a lembro o nome da parteira... (Narrativa de Elza Maria Ferreira Pontes, 2019)
}

Dona Elza demonstra em suas lembranças que o "i pro hospital” não existia em 
tempos passados e vividos por ela, a mesma nasceu em casa nas mãos de uma parteira. A narrativa desta trabalhadora nos faz refletir o quanto a construção do saber diário, em relação as práticas de cura exercidas a partir das experiência vivenciadas, faz-se imprescindível a vida de quem reside em áreas de matas, rios, igarapés, as quais consubstanciam-se nas primeiras escolhas frente a necessidade de restabelecer o equilíbrio orgânico, a saúde, de modo a harmonizar os estados bio-psíquico-espiritual.

A crença em se curar através dos saberes tradicionais faz-se tão presente entre os (as) moradores (as) do Cupijó que buscam se fundamentar através dos conhecimentos formais, a exemplo dos compêndios que apresentam orientações acerca das produções para cura que se alicerçam nas plantas medicinais. A respeito disso, destacamos o interesse de dona Elza em buscar conhecer com mais propriedade sobre o poder que determinadas ervas podem apresentar para tratar um dado problema de saúde. Sendo assim, essa perspectiva é destacada no seguinte trecho de seu discurso:

\begin{abstract}
Que eu tenhu um livrinho aí...Aí...Lá riu vou olhá as vezi é tau coisa é...Essi livro...Eu tenhu um livro aí qui era da mamãe, qui ela pediu, logo qui o papai morreu, né. Tá fazendu uns vinte e três anos. Aí a mamãe...Poque aí a mamãe, um dia um rapaz passou lá vendendo, aí era livro de medicina, aí mamãe cumpro. Naquela época era vinte e três reais...Aí mamãe compru, era caro, aí eu truce. Aí com tempo eu truce ele pra cá. Aí quando as vezi senti assim alguma coisa, aí eu vou lá $e$ olho, tal coisa é bom, enti vai cata por aí e cata, cata e faz, né. A erva, seje lá qui fô.Aí ó, agora eu pedi nu catáligo, uns livrinho qui vi, aí eu pedi e veiu, us livrinho. As vezi quando tô cum tempu, eu pegu tudu, né. Pra diabete, pra colesterol, pressão, essas cuisa. Aí, isso aí enti já vai...Né, eu quero, é...Arruma essas evas, pra fazê us remédio. genti tendo, genti faz. Poque aí, as vezi genti compra quando genti tem dinheiro, quando genti num tem...Muitos eu inda num comprei poque falta $o$ dinheiro pra cumpra pra trazê, chega tê. E na ora qui ti precisa, ti pega, faz u chá i toma...Mas, tem. (Narrativa de Elza Maria Ferreira Pontes, 2019)
\end{abstract}

No que tange à escolha de Dona Elza, como itinerário terapêutico, registramos que a mesma somou aos conhecimentos advindos das práticas tradicionais, construídos a partir do que se frutificou dos seus antecedentes, os saberes sobre produtos naturais reunidos em livro que foi oportunizada a conhecê-lo por intermédio de sua genitora, o qual auxilia nossa colaboradora, quando enfrenta enfermidades.

Diante das memórias de dona Elza, notamos o quanto se faz importante as práticas de curas tradicionais, enquanto moradora do Cupijó e seguidora dos aprendizados dos mais velhos, assim como de todo conhecimento que a leve a aperfeiçoar suas ações, como os 
apresentados pelos livros que se baseia para realizar o tratamento dos problemas de saúde que a comete a si e a quem a rodeia.

A questão do itinerário terapêutico, também está presente nas memórias de mais um de nossos narradores, o senhor Erinaldo, assim como ocorreu com os outros sujeitos sociais envolvidos neste estudo; encontra-se atrelado aos saberes tradicionais, possivelmente, por se fazerem presentes no cotidiano desses moradores e moradoras desde do primeiro contato com o mundo extra uterino e principalmente devido a linguagem agir em nossas vidas mesmo antes de nossa existência, afinal esta vive em funcionamento, causando sentindos antes e após nossa existência. Essa percepção é evidenciada no diálogo realizado com o senhor Erinaldo, a medida que faz um mergulho em sua memória remota e nos compartilha a respeito do primeiro contato que teve com o ar atmosférico, o qual se deu sobre os cuidados de uma parteira: "Nasci lá mesmo, no meio du matu, na mão de parteira inda. O nome da parteira é Joana. Olhi, o parto foi, foi bem”.

Importante destacarmos que a linguagem ocupa hoje um lugar central na sociedade, pois é mediadora das relações do homem com seu entorno. Por seu caráter simbólico, é constitutiva e transformadora da realidade, daí a importância de conhecermos seu funcionamento para compreendermos os discursos que são produzidos e circulam na sociedade, ao seu Erinaldo trazer em sua narrativa detalhes de seu parto, de um acontecimento do qual ele ainda não estava presente e do qual se lembra pela memória falada pelos seus pais, este nos reforça como as relações dos cuidados do corpo, do nascer em meio as matas eram mediadas naquela sociedade.

Nesse sentido, entendemos que a linguagem, em sua relação com a sociedade, é compreendida como movimento, que sempre nasce de algo já dito, concebida como parte do que é o próprio do homem, enquanto ser histórico e simbólico. Desse modo, a linguagem adquire importância fundamental para que possamos compreender além do já dito e, especialmente aquelas esquecidas, apagadas e silenciadas pela historiografia oficial.

Segundo os pressupostos de Orlandi (2002), "repetição histórica é a que desloca, a que permite o movimento porque historiciza o dizer e o sujeito, fazendo fluir o discurso, nos seus percursos, trabalhando o equívoco, a falha, os implícitos, atravessando as evidências do imaginário e fazendo o irrealizado irromper no já estabelecido".

É essa repetição que nos interessa, uma vez que a linguagem é como um curso corrente de águas fluidas que irrompem movimentos inusitados, irrepetíveis, singulares. É nesse ir e vir das memórias entrelaçadas pelo individual, oficial e coletivo que o nosso olhar se debruçará na tentativa de compreender cada narrativa aqui analisada, dando 
inteligibilidade aos dizeres diversos.

Retornando ao nosso dialogo com o senhor Erinaldo, observamos que durante os dias da semana este desloca-se até a cidade de Cametá para garantir uma renda para auxiliar no sustento da família através do trabalho em construção civil. Além dessa atribuição, nas terras de seus familiares realizam alguns cultivos como o de mandioca, milho, açaí, entre outros. No entanto, quando usam de todos os recursos advindos dos aprendizados adquiridos no dia-a-dia e não conseguem solucionar seus agravos de enfermidades, recorrem, em último caso, aos recursos e estruturas provenientes da Ciência Médica, das drogas farmacológicos, entre outros pertencentes a categoria dos conhecimentos formais.

\footnotetext{
Mas só qui depus que naci qui complico. Ela passo mal...Tivi qui vi, fica internada. Quase qui ela morri. De lá veiu pra cá po hospital já, dois dia parece...Escapo de morre...Fui lá e vortou. Naquela época era só parteira, só era nu caso...Pariu a mulherada. Era só aqui. Pa vim era aquela dificuldade pa vim. Era difícil carro naqueli tempu inda. Isso nera oitenta e dois. Aestrada tava começando sá, estrada í. Ulha... Dependia da doença, né. Cê...Negóciu de febri... Is...Oprimeiru medicamentu era AAS...Infanti e se nãomelhorassi...Procurava o rumo di cidadi. Naqueli tempu era a clínica da bera, ondi atendiu mais rápidu.." ( Narrativa de Erinaldo Pontes Silva, 2019)
}

Novamente na narrativa de Erinaldo percebe-se que há uma relação de intimidade traçada com os conhecimentos natos provenientes de suas vivências, diante de um processo de saúde e doença, sendo a escolha das práticas de cura tradicional a base do tratamento primário de saúde para cura do corpo. Erinaldo alerta ainda para as dificuldades de ter acesso ao atendimento médico de imediato, seja devido as estradas ou até mesmo para adquirir os remédios nas farmácias.

Os nossos narradores e narradoras optaram por utilizar da cultura popular, de seus saberes, das práticas de cura como forma de tratamento ou prevenção às doenças como primeira opção, por fatores diversos de estarem em meio às matas, às margem do rio e igarapés, e embora tenham acesso a remédios farmacológicos em algum momento; os conhecimentos dos mais velhos ainda são passados de geração a geração nestas localidades funcionando como um acontecimento discursivo, histórico e social para manutenção de saberes locais.

Procuramos, através das narrativas dos moradores do Cupijó, trazer à tona experiências e saberes que são transmitidos de geração a geração, principalmente pela oralidade, para que possamos compreender os saberes e linguagens das práticas de cura no/ 
do Cupijo através do discurso e da memória.

\section{Algumas inconclusões}

Ouvir, interpretar os discursos sobre o itinerário terapêutico, as práticas de cura em um território da Amazônia Tocantina, sem dúvida, consistiu em uma oportunidade de contribuir para inserir na literatura os saberes existentes nos discursos dos moradores (as) das matas e margens do rio Cupijó, assegurando que as palavras não consistem em propriedade particular e que a linguagem só faz sentido porque se "inscreve na história." Elas significam pela história e pela língua. O sujeito diz, pensa que sabe o que diz, mas não tem acesso ou controle sobre o modo pelo qual os sentidos se constituem nele." (ORLANDI, 2015, p. 32).

Diante disso, buscamos conhecer, através do discurso, da memória dos sujeitos sociais envolvidos neste estudo a representatividade do que consideram pertinente a sua vivência, consistiu em um exercício instigante e uma maneira de valorizar e divulgar conhecimentos peculiares que vem resistindo às práticas contemporâneas da medicina chamada "moderna".

Foi através das histórias de vida de nossos narradores e narradoras, parceiros desta pesquisa, de suas memórias e discursos que pudemos compreender as práticas de cura como uma arte que se (re) significa em tempos diversos a partir de suas experiências com a natureza e as formas de viver em um pequeno pedaço dessa imensa Amazônia Brasileira.

A arte de curar, é desta forma, um oficio, um aprendizado interagido de geração em geração, de forma que o sujeito aprende observando, ouvindo e ou sentindo as práticas de cura, resistindo, (re) significando em diferetes tempos maneiras de fazer, mantendo tradições dos povos tradicionais das matas amazônicas, seja por tradição, fé, resistência ou necessidade.

\section{REFERÊNCIAS}

ALVES, P. C.; SOUZA, I. M. A. Escolha e avaliação de tratamento para problemas de saúde: considerações sobre o itinerário terapêutico. In: RABELO, M. C. et al. Experiência de doença e narrativa. Rio de Janeiro: Editora Fiocruz, 1999.

ALVES, Paulo. C. Cultura: múltiplas leituras. Bauru, SP; Salavdor, BA: EDUSC; EDUFBA; 2010

ALVES; Fernando P. Paiva, Carlos Henrique. HOCHMAN, Gilberto. História, saúde e seus trabalhadores: da agenda internacional às políticas brasileiras. Ciência \& Saúde Coletiva, Rio de Janeiro: ABRASCO - Associação Brasileira de Saúde Coletiva. v.13, n. 3, 2008. 
BEVILACQUA, H. G. C. R. Planejamento de horta medicinal e comunitária. Divisão Tec. Esc. Municipal de Jardinagem / Curso de Plantas medicinais - São Paulo: 2010.

Disponível em: http://www.google.com.br/q=nuplan+plantas+medicinais.

BOSI, Ecléa. Memória e Sociedade, lembranças de velho. São Paulo: Companhia das Letras, 1994.

CERTEAU, Michel de. A Invenção do cotidiano. 1. Artes de fazer. São Paulo: Ed. Vozes, 1994.

COUTO, Varlei Rodrigues do. Memórias na sombra, sombras da memória: a construção da zona e o nascimento da puta.Entremeios, v. 3, n. 1, jul. 2011. Pouso Alegre, UNIVÁS, 2011.

FOUCAULT, M. História da loucura: na idade clássica. 9 ed. São Paulo: Perspectiva, 2010. (Trabalho original publicado em 1964)

GADELHA, C. S.; PINTO JUNIOR, V. M.; BEZERRA, K. K.; PEREIRA, B. B.;

MARACAJÁ, P. B. Estudo bibliográfico sobre o uso das plantas medicinais e fitoterápicos no Brasil.Revista Verde, Mossoró, v. 8, n. 5, 2013.

GERHARDT, T. E. Itinerários terapêuticos em situações de pobreza: diversidade e pluralidade. Cadernos de Saúde Pública, Rio de Janeiro, v. 22, n. 11, 2006.

GOMES, R. (et al). As representações sociais e a experiência das doença. Cad. Saúde Pública, Rio de Janeiro, 18(5), set-out, 2002.

LANGDON, E.J.; MAJ-LIS, F.; MALUF, S.W. Um balanço da antropologia da saúde no Brasil e seus diálogos com as antropologias mundiais. Anuário

Antropológico,2011I,Disponívelem:http://www.dan.unb.br/index.php?option=com_conten t\&view=article\&id=168\%3Aanuario-antropologico-sumario-

$20111 \&$ catid $=21 \% 3$ Aproducao-cientifica-anuario-antropologico \&Itemid $=32$

MÂNGIA, E.F.; MURAMOTO, M.T. Itinerários terapêuticos e construção de projetos terapêuticos cuidadores. Revista de Terapia Ocupacional, São Paulo, USP, São Paulo, 2008.

MINAYO, Maria Cecília de Sousa. O diálogo necessário entre a epidemiologia e as ciências sociais e humanas na promoção da saúde. In: Inf. Epidemiol - SUS. Brasília, v. 09, n.04, 2000. Disponivel

em:http://scielo.iec.gov.br/scielo.php?script=sci_arttext\&pid=S0104-16732000000400001

ORLANDI, Eni Puccinelli. Análise de Discurso: princípios e procedimentos. 12. ed.

Campinas: Pontes, 2015a.

ORLANDI, Eni Puccinelli. Apresentação. In:ORLANDI, Eni Puccinelli. (Org.).

Instituição, Relatos e Lendas:Narratividade e Individuação dos Sujeitos. Campinas:

Editora da Unicamp, 2016.

ORLANDI, Eni Puccinelli. As formas do silêncio: no movimento dos sentidos. Campinas, Ed. da UNICAMP, 2002.

SANTOS, A. O.; RIBEIRO, R. Saúde, doença e cura no Candomblé: ação profilática e terapêutica em espaço de religiões brasileiras de matrizes africanas.In:MANDARINO, Ana Cristina de Souza; GOMBERG, Estélio. (Org.). Candomblés: encruzilhadas de ideias, Coleção E-Livro, Salvador: EDUFBA, v. 01, 2015.

SARLO, Beatriz. Paisagens Imaginárias. São Paulo: Edusp, 1997.

Recebido em 22/05/2020. Aceito em 17/09/2020. 